\title{
Author Correction: Deciphering eukaryotic gene-regulatory logic with 100 million random promoters
}

Carl G. de Boer (iD), Eeshit Dhaval Vaishnav (D), Ronen Sadeh (D), Esteban Luis Abeyta (D), Nir Friedman (iD) and Aviv Regev (D)

Correction to: Nature Biotechnology https://doi.org/10.1038/s41587-019-0315-8, published online 2 December 2019.

In the version of this article initially published, a negative sign was missing negating the exponent in each of the three instances of the equation for accessibility, appearing in Fig. 2c, Methods section "Billboard model of transcription" and Supplementary Fig. 9. The correct equations are, respectively, as follows:

$$
\begin{gathered}
\Omega=\frac{1}{1+\mathrm{e}^{-\left(\mathrm{DB} \times P+c_{p}\right)}} \\
\Omega_{\mathrm{p}}=\frac{1}{1+\mathrm{e}^{-\left(c_{p}+\Sigma^{T F x} \mathrm{DB}_{\mathrm{px}} P_{x}\right)}} \\
\Omega=\frac{1}{1+e^{-\left(D B \cdot P+c_{p}\right)}}
\end{gathered}
$$

The correct equation was used in all analyses. The errors have been corrected in the PDF and HTML versions of the article.

Published online: 13 August 2020

https://doi.org/10.1038/s41587-020-0665-2

(c) The Author(s), under exclusive licence to Springer Nature America, Inc. 2020

\section{Author Correction: Detection of SARS-CoV-2 in nasal swabs using MALDI-MS}

Fabiane M. Nachtigall, Alfredo Pereira, Oleksandra S. Trofymchuk and Leonardo S. Santos (iD)

Correction to: Nature Biotechnology https://doi.org/10.1038/s41587-020-0644-7, published online 30 July 2020.

In the version of this article initially published online, no accession code was given for the raw data. PRIDE repository accession code PXD021388 has been added to the Data Availability section in the PDF and HTML versions of the article.

Published online: 17 September 2020

https://doi.org/10.1038/s41587-020-0701-2

(c) The Author(s), under exclusive licence to Springer Nature America, Inc. 2020 